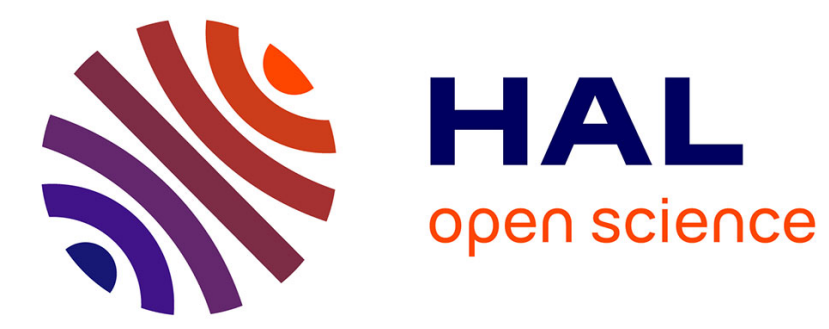

\title{
CONTROL OF A SELF-ALIGNED W SILICIDE PROCESS BY ANNEALING AMBIENCE
}

J. Torres, J. Palleau, N. Bourhila, J. Oberlin, A. Deneuville, M. Benyahia

\section{To cite this version:}

J. Torres, J. Palleau, N. Bourhila, J. Oberlin, A. Deneuville, et al.. CONTROL OF A SELF-ALIGNED W SILICIDE PROCESS BY ANNEALING AMBIENCE. Journal de Physique Colloques, 1988, 49 (C4), pp.C4-183-C4-186. 10.1051/jphyscol:1988437 . jpa-00227935

\section{HAL Id: jpa-00227935 https://hal.science/jpa-00227935}

Submitted on 1 Jan 1988

HAL is a multi-disciplinary open access archive for the deposit and dissemination of scientific research documents, whether they are published or not. The documents may come from teaching and research institutions in France or abroad, or from public or private research centers.
L'archive ouverte pluridisciplinaire HAL, est destinée au dépôt et à la diffusion de documents scientifiques de niveau recherche, publiés ou non, émanant des établissements d'enseignement et de recherche français ou étrangers, des laboratoires publics ou privés. 


\title{
CONTROL OF A SELF-ALIGNED W SIJICIDE PROCESS BY ANNEALING AMBIENCE
}

\author{
J. TORRES, J. PALlEAU, N. BOURHILA, J.C. OBERLIN, A. DENEUVILLE* and \\ M. BENYAHIA* \\ CNET, PB 98, F-38243 Meylan Cedex, France \\ *CNRS, BP 166x, F-38042 Grenoble Cedex, France
}

Bésumé- Pour les technologies submicroniques,des étapes de metallisation autoalignées sont de plus en plus nécessaires. La formation autoalignée du siliciure de tungstene WSi2 par réaction entre W et $\mathrm{Si}$ a pu être maitrisée en réalisant des recuits sous oxygène et sous ammoniac. La formation latérale du siliciure est alors évitée même sur des espaceurs d'oxyde d'épaisseur $60 \mathrm{~nm}$.

Abstract-With devices at submicronic dimensions, self-aligned processes are becoming of increasing interest. The self aligned $W$ silicide formation by localised reaction between $W$ and $S i$ has been controlled using reactive atmosphere, oxygen and ammonia, during furnace annealing . No lateral silicide formation over SiO2 spacers, only $60 \mathrm{~nm}$ thick, has been observed.

\section{1-INTRODUCTION}

Refractory metal silicides are more and more widely used in semiconductor technology due to their resitivity as materials for gate interconnections, contacts on source and drain areas, and as a first buried metallic layer for local interconnections.For ultra large scale integration, with devices at submicronic dimensions, self aligned silicidation is becoming of increasing interest.The self aligned process can be achieved either by selective deposition of the silicide layers or by direct reaction, induced by thermal annealing, between the refractory metal deposited over the whole wafer and the underlying silicon occurring only at localised points where these two materials come into contact .On the other hand the reaction between the refractory metal and oxidized silicon surface cannot take place.This latter approach is known as the salicide process. The critical step in such a scenario consists of the ability to well control the metal silicon reaction to avoid any lateral silicide formation over $\mathrm{SiO}_{2}$ spacers, only a few thousand angstroms wide separating the silicide areas. Without this control bridging between the gates sources and drains could occur.

To make sure that the silicide process works properly the operating range for annealing time and temperature must be large enough to allow for control and reproducibility of the process. For this it appears necessary to slow down the silicide growth kinetics by inducing, at the surface of the metal layer, a second reaction between the metal and a reactive annealing atmosphere. Consequently a stable state of equilibrium will be reached between the metal silicide phase and the metal compound formed with the reactive atmosphere.Titanium is the refractory metal by far the mosi widely accepted for this technology /1/.The $\mathrm{TiSi}_{2}$ growth kinetics has been found to be blocked by the formation of $\mathrm{TiNi}_{x}$ compounds during thermal annealing under an $\mathrm{N}_{2}$ flow. This paper presents recent decisive progress towards the control of the self aligned $\dot{W}$ silicide formation . 


\section{2-EXPERIMENTAL}

Up to now silicide technology has not worked using W.It is difficult to achieve on the W/Si reaction due to the hight sensitivity of the reaction to small amounts of oxygen both at the W/Si interface and trapped in the $\mathrm{W}$ layer during metal deposition/2/ Moreover tungsten does not react with $\mathrm{N}_{2}$. On the contrary $W$ reacts with oxygen,but in this case the reaction occurs so fast that tungsten is completely oxidized before the silicide reaction even begins. Recently $W$ nitridation has been studied using ammonia. The $W N_{x}$ compounds growth kinetics start at $550^{\circ} \mathrm{C}$ but seem to occur too fast compared with the $W$ silicide formation which is generally blocked.

To overcome these difficuties encountered when using oxygen or $\mathrm{NH}_{3}$ as the reactive annealing atmosphere the following solution has been envisaged.The $W O_{x}$ and $W N_{x}$ growth kinetics can be controlled by limiting the amount of reactive gas (oxygen or ammonia) in the annealing atmosphere.Consequently these reactions can be slowed down enough to allow $\mathrm{W}$ silicide formation at the W/Si interface. By varying the oxygen (or $\mathrm{NH}_{3}$ ) partial pressure in the annealing atmosphere it is perfectly possible to control the state of equilibrium between the $\mathrm{WO}_{\mathrm{x}}$ (or $\mathrm{WN}_{\mathrm{x}}$ ) phase and the $\mathrm{WSi}_{2}$ phase at a fixed annealing temperature.On the other hand, when the oxygen (or ammonia) partial pressure has been fixed, it is perfectly possible to control the reacted silicide thickness by varying the annealing temperature. Thus the $W$ silicide process can be optimized by adjusting two free parameters :the partial pressure of the reactive atmosphere and the annealing temperature.For the experimental study silicon wafers with $600 \mathrm{~A} \mathrm{SiO}_{2}$ on the top were used.By reactive ion etching (RIE) two reverse patterns were obtained:either $40 \mathrm{um}$ wide silicon lines with 4 um wide SiO2 spacers or4um wide $\mathrm{Si}$ lines with $40 \mathrm{um}$ wide $\mathrm{SiO}_{2}$ spacers. Over the whole patterned wafer a $50 \mathrm{~nm}$ thick $\mathrm{W}$ layer was sputtered. Residual vacuum values of a few $10^{-8} \mathrm{~T}$ were reached in the sputtering system before starting the $W$ deposition. The $W$ silicon reaction was first studied on unpatterned Si wafers by using argon during thermal annealing. At $700^{\circ} \mathrm{C}$ the reaction is complete only for annealing times of about one hour, but at $750^{\circ} \mathrm{C}$ the annealing time is reduced to less than a quarter of one hour. Annealings under reactive atmospheres of oxygen and ammonia, were then performed using patterned and unpatterned samples at annealing temperatures in the $700^{\circ} \mathrm{C}, 1000^{\circ} \mathrm{C}$ range and for annealing times much greater than necessary for a complete reaction of the $W$ layer with the silicon. The patterned samples were observed by SEM and $X$ ray diffraction, the unpatterned samples by RBS, nuclear reaction and $X$ ray diffraction.

\section{SEM observations}

The photographs shown in Fig 1 and 2 correspond respectively to thermal annealing with oxygen and ammonia. As the $\mathrm{SiO}_{2}$ spacers are only $60 \mathrm{~nm}$ thick any lateral silicide formation of this order of magnitude over such spacers can easily be observed. Figure 1 a shows the silicide grown at $850^{\circ} \mathrm{C}$ for $4 \mathrm{mn}$, by using dilute oxygen and after chemical etching of $\mathrm{WO}_{\mathbf{x}}$. The silicide is perfectly aligned on the silicon line and no lateral silicide formation over the $\mathrm{SiO}_{2}$ surfaces is observed. Fig $1 \mathrm{~b}$ shows the edge of a $\mathrm{SiO}_{2}$ line at the boundary with a silicide area.The salicide process has been well controlled. Fig $2 a$ shows cross sections of patterned samples annealed at $850^{\circ} \mathrm{C}$ for $4 \mathrm{mn}$ under dilute $\mathrm{NH}_{3}$. The view in Fig 2a has been taken before chemical etching of $\mathrm{WN}_{x}$ formed on $\mathrm{SiO}_{2}$. The difference in the thickness of the deposited layer either over the $\mathrm{SiO}_{2}$ surface or over the Si surface underlines the formation of two different phases over these two different surfaces. The photograph of Fig $2 b$ shows the patterns after chernical etching of $W N_{x}$. Here also the $W$ salicide process has been well controlled. 

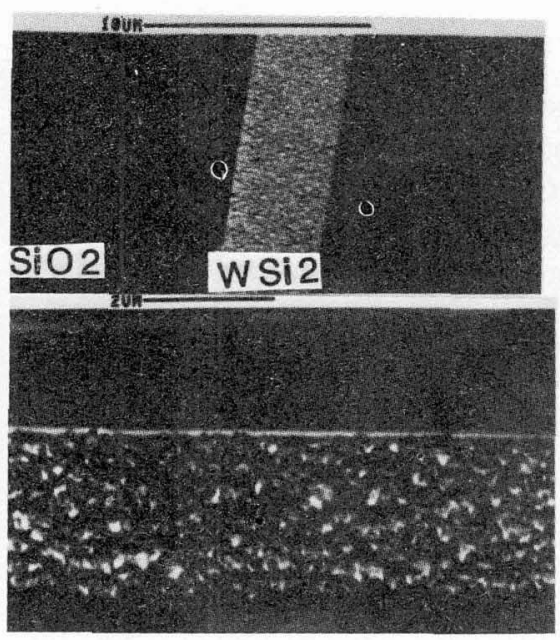

Fig. 1-SEM observation of self aligned silicide grown at $850^{\circ} \mathrm{C}, 4 \mathrm{mn}$, under oxygen a-plane view

b-edge of a SiO2 spacer, $60 \mathrm{~nm}$ thick, at the boundary with a silicide area

\section{R.B.S and nuclear reaction}

Annealing under $\mathrm{NH}_{3}$ at atmospheric pressure (Fig 3):

In Fig $3 \mathrm{a}$ the squares correspond to thermal annealing at $700^{\circ} \mathrm{C}$ for one hour.Tungsten and silicon have not reacted. The corresponding nitrogen profile in $\mathrm{Fig} 3 \mathrm{~b}$ obtained using the nuclear reaction ${ }^{14} \mathrm{~N}(d, \alpha)^{12} \mathrm{C}$ shows two peaks localised at the free surfaces of the sample $\left(4 E_{16} \mathrm{at} / \mathrm{cm}^{2} \mathrm{dose}\right)$ and the W/Si interface (3.1E16 at/cm ${ }^{2}$ dose).

The crosses in Fig $3 a$ are obtained when annealing at $750^{\circ} \mathrm{C}$ for one hour. A WN 0.7 compound has been found on the top of the layer, followed by a thick sublayer of unreacted $\mathrm{W}$. The corresponding $\mathrm{N}$ profile shows a peak (4E16 at/cm2) localised at the W/Si interface.By increasing the temperatures for isochronal annealings the amount of $\mathbf{N}$ into $\mathrm{W}$ increases slowly. Finally a homogeneous $\mathrm{WN}$ stoichiometry is found when annealing at $900^{\circ} \mathrm{C}$ and above.From RBS and nuclear reaction, observations two important conclusions can be reached

1) $N$ diffuses through the layer without precipitate $W N_{x}$ compounds for annealing temperatures up to $750^{\circ} \mathrm{C}$.As $\mathrm{N}$ solubility in $\mathrm{W}$ is very low, the $\mathrm{N}$ diffusion must occur at the $\mathrm{W}$ grain boundaries. The driving force could be the formation at the Si surface of $\operatorname{SiN}_{X}$ compounds thermodynamically favorable with regard to $W N_{x}$ compounds.

2)The growth kinetics rate for the $W N_{x}$ phases are low compared with the $\mathrm{WSi}_{2}$ kinetics

3)As a result of the preceding remarks, it appears to be the rapid accumulation of $N$ at the W/Si interface which blocks the silicon diffusion and impedes the $\mathrm{WSi}_{2}$ formation.

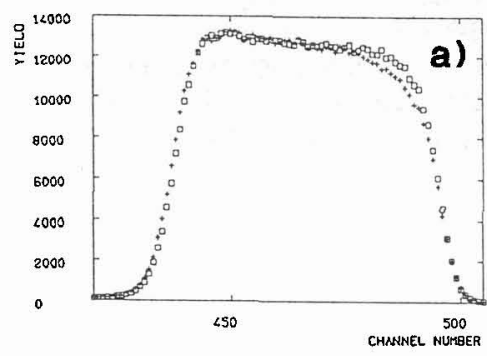

$700^{\circ} \mathrm{C}$

$750^{\circ} \mathrm{C}$

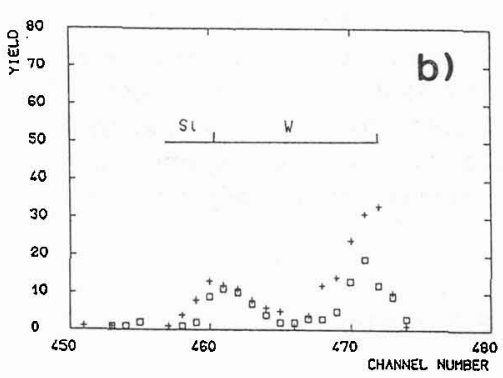

Fig.3 a-RBS spectra of $W$ after annealing under atmospheric pressure b-corresponding $N$ profiles by nuclear reaction 
Annealing under oxygen atmospheric pressure:

The $\mathrm{W}$ is completely oxidized and forms the $\mathrm{WO}_{3}$ phase for annealing temperatures above $500^{\circ} \mathrm{C}$. The RBS spectrum in Fig 4 corresponds to thermal annealing at $400^{\circ} \mathrm{C}$ for one hour. The corresponding oxygen profile has bien obtained using the nuclear reaction $\left({ }^{16} \mathrm{O}(\mathrm{d}, \alpha)^{14} \mathrm{~N}\right) . \mathrm{A} \mathrm{WO}$ layer is found at the free surface covering an oxygen free unreacted $W$ layer .Moreover, not any oxygen peak at the $W / S i$ interface has been observed. The $W$ behaviour with oxygen is found to be very different from the behaviour found with $N$ :

1)Free oxygen does riot diffuse through the $W$ layer to accumulate at the W/Si interface

2) The $\mathrm{WO}_{3}$ phase forms at temperatures as low as $400^{\circ} \mathrm{C}$, and its growth kinetics is very fast compared with the $\mathrm{WSi}_{2}$ growth kinetics

3)As a result,it is the rapid formation of $\mathrm{WO}_{3}$ which impedes the formation of WSi 2 .
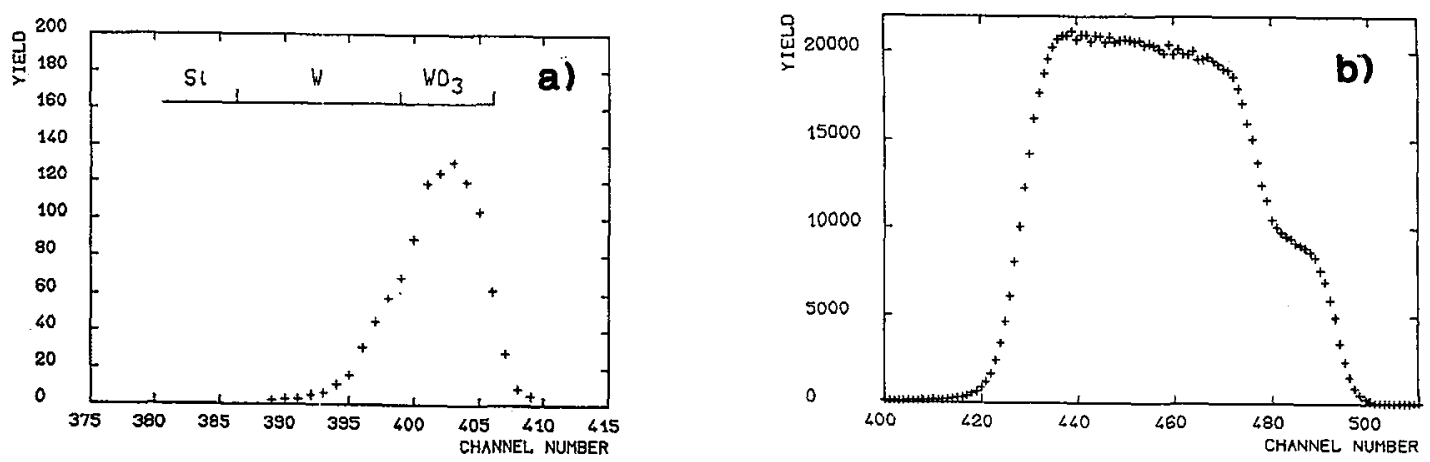

Fig.4 a-RBS spectrum of $W$ after annealing under oxygen at atmospheric pressure b-corresponding $O$ profile obtained by nuclear reaction

$X$ ray diffraction measurements and resistivity measurements have also been performed and the results confirm the RBS observations.

\section{3-CONCLUSION}

Self aligned $W$ silicide formation has been controlled by using oxygen and ammonia as reactive annealing atmosphere. After furnace thermal annealing, $W$ nitride and $W$ oxyde can be selectively removed using a chemical etching which leaves only the WSi2 phase. Moreover, with respect to important processing aspects -dopants redristibution between WSi2 and poly or monocrystalline Si allowing to form very shallow junctions below silicided contacts, compatibility of the silicide with a first W C.V.D. interconnection level/3/- WSi2 presents a very interesting behaviour making it very attractive for self aligned silicide processes.

\section{REFERENCES}

11/ M. E. Alperin, T. C. Hollaway, R.A.Haken, C.D.Gosmeyer, R.V.Karnaugh and W.D.Parmantie, IEEE Trans .Electron devices ED_32,141,1985 /2/G.Bomchil, G.Goltz and J.Torres, Thin Solid Films, 59, 1986

/3/F.C.Shone, K.C.Saraswat and J.D.Plummer, IEDM Technical Digest, 407, 1985 